\title{
O PROCESSO EDUCATIVO NO PENSAMENTO MARXISTA
}

\author{
Raquel Dias Araujo ${ }^{1}$
}

\section{Resumo:}

O presente artigo, intitulado "O processo educativo no pensamento marxista", traz os resultados da pesquisa desenvolvida no âmbito do Projeto de Iniciação Cientifica da Universidade Estadual do Ceará - IC/UECE. A pesquisa assumiu como objetivo geral perscrutar nas obras de Marx e Engels os esboços de uma concepção de Educação de matiz emancipatória, identificando suas principais categorias e buscando aferir, a partir de seus intérpretes no campo da educação, o papel do complexo educacional no processo de emancipação humana. Trata-se de um trabalho de natureza teórica, realizado mediante pesquisa bibliográfica, durante a qual, no primeiro momento, detivemos nossa atenção sobre a análise da categoria Educação nas obras de Marx e Engels, tomando como referência a coletânea "Textos sobre educação e ensino" (MARX; ENGELS, 2004). Partindo daí, debruçamo-nos sobre a contribuição de alguns intérpretes que se dedicaram a estudar acerca do tema da Educação, à luz do referencial marxiano. Para tanto, selecionamos uma amostra das obras, a saber, Mészáros (1981, 2005), Tonet (2005), dando destaque para a análise da obra de Saviani, Pedagogia Histórico-Crítica (2003). A problemática foi enfrentada à luz da ontologia marxiana, considerando, portanto, a educação em sua complexidade histórico-social. Por esse ângulo, buscamos identificar os limites e reconhecer as possibilidades de uma intervenção pedagógica no interior dos sistemas educativos, no contexto das sociedades de classes e, em particular, no capitalismo, no horizonte da emancipação humana.

Palavras-chave: Marxismo, Educação, Emancipação.

\begin{abstract}
:
The present paper is entitled as "The educational process in Marxist thought" and it presents the outcomes of the study conducted in the ambit of the Project of Scientific Initiation at the State University of Ceará - IC / UECE. The research had as general purpose peering in the works of Marx and Engels the outlines of a conception of an emancipatory education, identifying its major categories and seeking to assess, from its performers in the educational field, the role of the educational complex on the process of human emancipation. This is a work of a theoretical nature that was performed by literature search, during which, at first, we directed our attention on the analysis of the Education category in the works of Marx and Engels, in reference to the compilation "Textos sobre educação e ensino" (MARX; ENGELS, 2004). Thenceforth, we focused on the contribution of some interpreters who dedicated themselves to study on the subject of Education in the light of the Marxian framework. For this purpose, we have selected a sample of works, namely, Mészáros (1981, 2005), Tonet (2005), giving emphasis on the analysis of Saviani's work, Historical-Critical Pedagogy (2003). The
\end{abstract}

\footnotetext{
${ }^{1}$ Doutora em Educação pelo Programa de Pós-graduação em Educação da UFC. Professora Adjunta do Centro de Educação da Universidade Estadual do Ceará - CED/UECE, lotada no curso de pedagogia. Email: raquel.dias@uece.br.
} 
issue was addressed in the light of Marx's ontology, thus considering education in its historical and social complexity. From this angle, we seek to identify the limits and recognize the possibilities of a pedagogical intervention within the educational systems, in the context of class societies and, in particular, in capitalism, the horizon of human emancipation.

Keywords: Marxism, Education, Emancipation.

\section{Introdução}

O estudo sobre os fundamentos teóricos e políticos da educação no pensamento marxista justifica-se, nesse momento, pela necessidade de responder teoricamente, no campo da educação, às várias tentativas discursivas e práticas de imprimir ao complexo educacional à supremacia sobre as relações sociais de produção,

[...] tomando o determinante pelo determinado e vice-versa. Com isso, a educação, de elemento socialmente determinante, passa a ser veiculada como determinante das relações sociais, sendo capaz, em consequência, de modificá-la pela força de seu intrínseco poder (SAVIANI, 2003, p. 12).

O resgate no pensamento marxiano, desde os clássicos, passando pelos contemporâneos, de uma concepção de educação de matiz emancipatória, que possa apontar como horizonte a formação de um ser humano na sua integralidade, torna-se, a nosso ver, uma necessidade da realidade concreta que se confronta diretamente com os rumos que a educação vem tomando em tempos de barbárie capitalista, que a transformou num objeto do mercado como outro qualquer.

No primeiro momento da investigação, procuramos identificar nas obras de Marx e Engels a origem de uma concepção emancipatória de educação, tomando como base para o estudo a coletânea de textos de Marx e Engels publicada pela Editora Centauro, intitulada "Textos sobre educação e ensino" (MARX; ENGELS, 2004). A referida coletânea tem a importância de identificar as obras de Marx e Engels que se referem à temática da educação, indicando-nos o caminho a percorrer. No segundo momento, buscamos nos autores contemporâneos da área da educação, que bebem na fonte do marximo, os elementos de análise necessários à compreensão do papel do complexo educacional no momento atual, delimitando os seus limites e apontando as suas possibilidades no processo de construção de uma sociedade emancipada. Nesse

\begin{tabular}{|l|l|l|l|l|}
\hline Qevista Dialectus & Ano 2 & n. 3 & Julho-Dezembro 2013 & p. 133-144 \\
\hline
\end{tabular}


caso, lançamos mão das contribuições de Mészáros (1981, 2005), Tonet (2005) e, com destaque, de Saviani (2003).

No intuito de alcançar os objetivos propostos, formulamos os seguintes questionamentos norteadores do processo investigativo: Quais os fundamentos teóricos e políticos de uma concepção emancipadora de educação? Que papel cumpre a educação na sociedade de classes, em particular na sociedade capitalista? Qual a contribuição da Pedagogia Histórico-Crítica para a compreensão do fenômeno educativo na sociedade atual? Em que medida a educação pode contribuir para o processo de emancipação humana?

$\mathrm{O}$ artigo está organizado em três partes que se complementam. Na primeira, apresentamos algumas considerações acerca da categoria educação em Marx e Engels, citando as obras nas quais o tema da educação é tratado tanto no aspecto mais geral como em sentido específico, destacando, ainda, os assuntos mais relevantes discutidos pelos autores. No segundo, buscamos situar a educação no contexto histórico, no sentido de averiguar a função assumida pelos sistemas educativos a partir da configuração da sociedade capitalista e da divisão do trabalho decorrente dela. No terceiro, tratamos das contradições que permeiam o complexo educacional, identificando seus limites e suas possibilidades no processo de construção da emancipação humana.

\section{Considerações preliminares acerca da categoria educação em Marx e Engels}

O trabalho realizado consistiu na investigação em torno dos fundamentos teóricos e políticos da educação no pensamento marxista, buscando identificar as possíveis origens de uma concepção emancipadora de educação em Marx e Engels, tomando como obra de referência "Textos sobre educação e ensino" (2004), uma coletânea de textos organizada pela Editora Centauro.

Vale registrar que Marx e Engels nunca escreveram um texto especificamente sobre o tema da educação e do ensino. As referências aos referidos temas podem ser encontrados ao longo de sua obra, tanto nos "Manuscritos Econômico-Filosóficos" (MARX, 1993) como em “O Capital” (MARX, 1996). Isto não quer dizer que as referências configurem apenas opiniões conjunturais desses autores acerca da temática estudada por nós.

\begin{tabular}{|l|l|l|l|l|}
\hline Qevista Dialectus & Ano 2 & n. 3 & Julho-Dezembro 2013 & p. 133-144 \\
\hline
\end{tabular}


A investigação nos permitiu observar que o tema da educação é tratado sob dois aspectos, no conjunto da obra dos dois autores: a) No sentido mais geral, concebida como o processo de formação humana; b) No sentido mais específico, vista sob seu processo histórico-social, desenvolvida em instituições escolares no contexto da sociedade capitalista.

Quanto ao primeiro aspecto, a educação é tratada na sua relação com o processo de produção da existência material do ser humano. Nesse aspecto, inseparável, porém, de natureza distinta, do próprio processo do vir a ser do homem, conforme desenvolveremos no próximo tópico. ${ }^{2}$

Observada em sua historicidade e na sua relação com os outros complexos que constituem a vida social, em particular, na sociedade capitalista, a educação, tratada por Marx e Engels, ainda que de maneira aleatória, ganha um sentido bastante específico no processo de reprodução social, uma vez que o ponto de partida da análise de Marx e Engels sobre a temática da educação é exatamente a crítica às situações que o capitalismo, a manufatura e a divisão do trabalho produziram, as quais se refletiram sobre os sistemas educativos.

A educação é tratada na sua concretude histórico-social, sob vários aspectos: 1) A instrução como componente da reprodução da força de trabalho; 2) A educação da classe trabalhadora na visão da burguesia; 3) A exigência de oferta de educação por parte da classe trabalhadora; 4) A crítica ao modelo de ensino ministrado nas escolas, dentre outros elementos. ${ }^{3}$

Os sistemas de ensino são avaliados a partir da sua organização em função da divisão do trabalho e da cisão entre trabalho intelectual e manual, sob a ordem do capital. Nesse sentido, Marx é categórico em afirmar que a fábrica seria o "[...] melhor método de embrutecimento [do trabalhador] [...]" (MARX; ENGELS, 2004, p. 33). ${ }^{4}$

Nossas reflexões incidem, mais particularmente, sobre o segundo aspecto. Desta feita, a hipótese central da pesquisa foi formulada em torno da compreensão de

\footnotetext{
${ }^{2}$ As referências ao tema da educação, compreendida em seu aspecto mais amplo, como processo de formação do ser humano em sua relação com o processo de produção da existência, podem ser conferidas nas seguintes obras: 1) A ideologia alemã (MARX; ENGELS, 1996); 2) As teses sobre Feuerbach (MARX, 1996); 3) Manuscritos econômico-filosóficos (MARX, 1993); 4) A questão judaica (MARX, 1993), dentre outras obras.

${ }^{3}$ As referências aos temas aludidos são encontradas nas seguintes obras: 1) A ideologia alemã (MARX; ENGELS, 1996); 2) Trabalho assalariado e capital (MARX, 1982); 3) O Capital (MARX, 1996); 4) A situação da classe trabalhadora na Inglaterra (ENGELS, 2008); 5) Instruções aos Delegados do Conselho Central Provisório - AIT, 1868 (IN: MARX; ENGELS, 2004); 6) Salário, preço e lucro (MARX, 2004); 7) Princípios básicos do comunismo (ENGELS, 1982), dentre outras.

${ }^{4}$ Citação retirada da obra A situação da classe trabalhadora na Inglaterra (ENGELS, 2008).
}

\begin{tabular}{|l|l|l|l|l|}
\hline Qevista Dialectus & Ano 2 & n. 3 & Julho-Dezembro 2013 & p. 133-144 \\
\hline
\end{tabular}


que o complexo educacional cumpre predominantemente uma função reprodutora nas sociedades de classes, mas que, apesar dessa determinação, é impossível negar seu caráter contraditório, como reflexo das próprias contradições sociais, nas quais a educação se situa e se desenvolve.

A questão central sobre a qual a pesquisa incidiu tratou da identificação dos limites e das possibilidades da intervenção de uma concepção emancipadora de educação no processo de emancipação humana. Tais reflexões já podem ser identificadas nas elaborações de Marx e Engels, mas estão melhores desenvolvidas em autores contemporâneos da área da educação, os quais se dedicaram a extrair da obra de Marx e Engels as premissas dessa concepção e desenvolvê-la, considerando as condições atuais. ${ }^{5}$

É importante registrar também o mérito dos editores da coletânea "Textos sobre educação e ensino", da qual lançamos mão para iniciar nosso trabalho investigativo. A coletânea localiza não apenas as obras nas quais Marx e Engels se referem aos temas da educação e do ensino, o que, per si, já seria uma grande contribuição, mas, além disso, os editores trazem na introdução uma explicação acerca da organização da coletânea, dos textos (ou trechos retirados dos originais) e dos temas tratados, conferindo, portanto, uma maior coerência aos textos elencados no livro.

Os textos de Marx e Engels foram agrupados em cinco temas, a saber: 1. Sistema de ensino e divisão do trabalho; 2. Educação, formação e trabalho; 3. Ensino, ciência e ideologia; 4. Educação, trabalho infantil e feminino; 5. O ensino e a educação da classe trabalhadora.

As referências a estes temas feitas por Marx e Engels estão distribuidas em várias obras, tais como: "A sagrada família” (2001), “A ideologia alemã” (MARX; ENGELS, 1996), "Manifesto Comunista" (2009), “O Capital” (MARX, 1996), “A origem da família, da propriedade privada e do Estado" (2010), "Crítica ao Programa de Gotha" (2012), "Salário, preço e lucro" (2004), dentre outras.

\section{A Categoria Educação concebida no Pensamento Marxista em sua complexidade social}

\footnotetext{
5 Dentre os autores contemporâneos que buscaram extrair da obra de Marx as premissas de uma concepção crítica de educação, destaca-se Mario Alighiero Manacorda, com a obra Marx e a Pedagogia Moderna (2007), a qual se tornou uma referência para os estudiosos marxistas do campo da educação. Não poderíamos deixar de citar também, dentre os nossos autores, o trabalho de Justino de Sousa Júnior, intitulado Marx e a crítica da educação (2011).
}

\begin{tabular}{|l|l|l|l|l|}
\hline Qevista Dialectus & Ano 2 & n. 3 & Julho-Dezembro 2013 & p. 133-144 \\
\hline
\end{tabular}


No processo de reprodução da existência humana, o ser humano entra em relação com a natureza e com os outros seres humanos, transformando a realidade existente e a si próprio, num processo complexo, que une a intencionalidade e ação, mediante o ato do trabalho. Por isso, dizemos que o trabalho é o ato fundante da sociabilidade humana. Como bem explicitou Marx (1996, p. 50),

[...] o trabalho, como criador de valores-de-uso, como trabalho útil, é indispensável à existência do homem, é necessidade natural e eterna de efetivar o intercâmbio material entre o homem e a natureza e, portanto, de manter a vida humana.

No entanto, a reprodução do ser social, ou seja, a sua continuidade exige várias mediações que se interpõem entre a consciência, que estabelece uma finalidade, e a ação propriamente dita sobre a causalidade a ser modificada. Assim, a escolha dos meios necessários à efetivação de um determinado fim se faz baseada no conhecimento o mais aproximado possível da realidade sobre a qual o ser humano pretende agir e modificar. A produção desse conhecimento sobre o real pode se realizar de maneira formal ou informal a depender da situação. Nesse sentido, o processo educativo, em sentido geral, mas, também, em sentido restrito, realiza-se como uma condição sine qua non, da reprodução da vida humana, sendo uma exigência crescente das sociedades modernas.

Aqui, destacamos a educação como uma das mediações chaves do processo de reprodução do ser social. Como explica Saviani (2003, p. 13):

[...] o trabalho educativo é o ato de produzir, direta e intencionalmente, em cada indivíduo singular, a humanidade que é produzida histórica e coletivamente pelo conjunto dos homens. Assim, o objeto da educação diz respeito, de um lado, à identificação dos elementos culturais que precisam ser assimilados pelos indivíduos da espécie humana para que eles se tornem humanos e, de outro lado e concomitantemente, à descoberta das formas mais adequadas para atingir esse objetivo.

Ora, nas sociedades primitivas, quando não existiam as diferenças de classe e a produção da existência era um ato coletivo, o processo educativo, apesar de distinto pela sua própria natureza, até certo ponto, confundia-se com o próprio processo do trabalho, uma vez que a educação, nesse momento, não institucionalizada, só justificava-se pela necessidade da continuidade do gênero humano. Isto significa que a reprodução do ser social exigia como condição imediata, o conhecimento profundo da natureza, para se proteger de suas intempéries e para tirar dela o melhor proveito.

A partir do momento que a raça humana se divide em classes sociais distintas e antagônicas como resultado do processo de apropriação privada dos meios de produção por uma parcela da minoritária da sociedade, a educação se institucionaliza e se

\begin{tabular}{|l|l|l|l|l|}
\hline Qevista Dialectus & Ano 2 & n. 3 & Julho-Dezembro 2013 & p. 133-144 \\
\hline
\end{tabular}


transforma numa ferramenta necessária ao processo de reprodução social atrelada à manutenção de um certo status quo. A escola como um elemento constituinte do Estado, órgão regulador das sociedades de classes, passa a ter papel central na institucionalização das normas e regras da vida social.

Nas sociedades antigas, baseadas em relações de produção escravagistas, a exemplo da Antiga Grécia, a escola assume o significado de "lugar do ócio", uma vez que a maioria da sociedade, constituída de escravos, não precisava da escola para aprender uma profissão e muito menos para incorporar as normas e as condutas da vida em sociedade.

Primeiro, porque aprendiam o ofício no próprio trabalho e, segundo, porque a vida social resumia-se à própria escravidão. Desse modo, a escola destinava-se aos filhos do sexo masculino dos proprietários de escravos, os quais frequentavam à instituição escolar para aprenderem a ser dirigentes da sociedade. O conhecimento era um instrumento de dominação e exploração de classe.

Nas sociedades medievais, nas quais a ordem social se hierarquizava pelos mandamentos da Igreja Católica, a escola, entendida como o "lugar do ócio com dignidade", assumia o papel de preparar a classe dominante nos ensinamentos do que era tido como sagrado. Assim, a escola auxiliava no processo de reprodução social orientado pelo pensamento religioso, então o pensamento dominante da sociedade. Os trabalhadores servis, assim como os escravos nas sociedades antigas, não precisavam frequentar a escola para aprender cultivar a terra, principal atividade econômica das sociedades feudais. A atividade intelectual realizada na escola era considerada uma atividade digna em oposição à atividade manual realizada pelos servos e os seus filhos. Nesse sentido, o conhecimento erudito produzido pela instituição escolar só poderia se destinar àqueles que eram dignos de recebê-lo.

Saviani (2003, p. 95) ressalta que nesses dois tipos de sociedades antiga/escravista e medieval/feudal,

[...] a escola aparecia como uma modalidade de educação complementar e secundária. Isto porque a modalidade principal de educação continuava sendo o trabalho, uma vez que a grande massa, a maioria, não se educava através da escola, mas através da vida, ou seja, através do processo de trabalho [...].

Com a instauração da ordem social capitalista e o advento da industrialização, a educação institucionalizada torna-se uma exigência, visto que o capitalismo se rege por códigos escritos e contratos formais. O trabalhador, agora, livre para negociar a sua força de trabalho, fará isso com base numa relação contratual, o que requer, 
minimamente, níveis adequados de escolarização. Por outro lado, o aprendizado de um ofício exige necessariamente, nesse contexto a mediação da escola, como a instituição especializada na qualificação da força de trabalho. Mészáros (1981) enfatiza essa ideia ao afirmar que as duas funções principais da escola na sociedade capitalista são: a reprodução da força de trabalho e a veiculação da ideologia dominante.

Em outro momento, o mesmo autor (2005, p. 35) ratifica a premissa acima aludida ao concluir que:

A educação institucionalizada, especialmente nos últimos 150 anos, serviu no seu todo - ao propósito de não só fornecer os conhecimentos e o pessoal necessário à máquina produtiva em expansão do sistema do capital, como também gerar e transmitir um quadro de valores que legitima os interesses dominantes $[\ldots]$.

Destarte, a função predominantemente reprodutora da instituição escolar nas sociedades de classe, não podemos negar que a sua generalização a partir da Revolução Francesa é uma conquista contraditória da classe trabalhadora, uma vez que expressa também uma demanda dos trabalhadores por educação que os prepare para intervir conscientemente no mundo para transformá-lo em seu benefício. A burguesia, embora busque ter um controle o mais rigoroso possível do sistema educativo, por meio do aparato do Estado, na tentativa de direcioná-lo ao cumprimento dos seus objetivos, não consegue controlá-lo in totem, pois o conhecimento produzido na escola não pode ser absolutamente controlado como os processos produtivos, por exemplo. $\mathrm{O}$ conhecimento, por mais fragmentado e alienante que seja, abre possibilidades de uma leitura do mundo antes inimagináveis. Por isso que importa e muito aos trabalhadores a apropriação do conhecimento, que lhe é cotidianamente negado, como uma forma de mantê-lo ignorante e submisso aos imperativos do capital.

Saviani (2003, p. 71) chama a atenção para o fato de que "[...] mesmo o aspecto reprodutor da educação é contraditório e não mecânico" por ser ele mesmo um reflexo da contradição essencial da sociedade de classes, que, no capitalismo, se expressa na antinomia entre capital e trabalho.

No entanto, vale frisar, com ajuda de Tonet (2005, p. 223), que:

A existência do antagonismo de classe, contudo, também implica no surgimento - sob formas explícitas ou implícitas - de outras propostas, com outros fundamentos, outros valores e outros objetivos. De modo que o campo da educação, como aliás toda a realidade social, é um espaço no qual se trava uma incessante luta, ainda que a hegemonia esteja sempre nas mãos das classes dominantes. Essas outras propostas, no entanto, sempre terão um caráter restrito, pontual, isolado. No caso da sociedade atual, uma proposta de educação emancipadora só poderá ser explicitada em seus elementos gerais, mas nunca poderá ser levada à prática como um conjunto sistematizado [...].

\begin{tabular}{|l|l|l|l|l|}
\hline Qevista Dialectus & Ano 2 & n. 3 & Julho-Dezembro 2013 & p. 133-144 \\
\hline
\end{tabular}


Em Pedagogia Histórico-Crítica, Saviani (2003) vai desenvolver uma teoria educacional, à luz do movimento histórico e das contradições das relações sociais capitalistas, que “[...] busca compreender a questão educacional a partir dos condicionamentos sociais" (p. 92). Trata-se, portanto, nas palavras do próprio autor (2003, p. 92),

\begin{abstract}
[...] de uma análise crítica porque consciente da determinação exercida pela sociedade sobre a educação; no entanto, é uma análise crítico-dialética e não crítico-mecanicista. Com efeito a visão mecanicista inerente às teorias crítico-reprodutivistas considera a sociedade determinante unidirecional da educação. Ora, sendo esta determinada de forma absoluta pela sociedade, isto significa que se ignora a categoria de ação recíproca, ou seja, que a educação é, sim, determinada pela sociedade, mas que essa determinação é relativa e na forma de ação recíproca - o que significa que o determinado também reage sobre o determinante. Consequentemente, a educação também interfere sobre a sociedade, podendo contribuir para a sua própria transformação.
\end{abstract}

A questão que se apresenta para a investigação nesse projeto de pesquisa, à luz da literatura referida, é saber em que medida a educação age sobre o determinante - o conjunto das relações sociais dominantes - por meio da ação recíproca, e quais as suas implicações concretas no processo de transformação social.

\title{
Reprodução, Contradição, Emancipação: categorias que se entrelaçam na Práxis educativa
}

Apresentamos neste artigo as conclusões preliminares da pesquisa. Nesse caso, destacamos os seguintes elementos que se entrelaçam:

1) Marx e Engels criticam o modelo educacional existente que se ergueu a partir da constituição da indústria moderna e da divisão do trabalho;

2) Defendem que, sob as condições de uma sociedade capitalista, as crianças e os adolescentes sejam protegidos dos efeitos nocivos da divisão do trabalho;

3) Observam que, mesmo sob as condições absolutamente inadequadas em que a educação das crianças e dos adolescentes se realiza, a articulação entre trabalho e educação contribui para o seu desenvolvimento;

4) Ainda defendem que, numa sociedade comunista, a educação possa assegurar "uma cultura técnica múltipla, bem como uma base prática para a educação científica", por meio da interligação com o trabalho.

Este último elemento pode ser identificado na famosa citação de Marx extraída das Instruções aos Delegados do Conselho Central Provisório, AIT (1868), na qual explicita que:

\begin{tabular}{|l|l|l|l|l|}
\hline Qevista Dialectus & Ano 2 & n. 3 & Julho-Dezembro 2013 & p. 133-144 \\
\hline
\end{tabular}


Por educação entendemos três coisas:

1) Educação intelectual;

2) Educação corporal, tal como a que se consegue com os exercícios de ginástica e militares;

3) Educação tecnológica, que recolhe os princípios gerais e de caráter científico de todo o processo de produção e, ao mesmo tempo, inicia as crianças e os adolescentes no manejo de ferramentas elementares dos diversos ramos industriais". (MARX; ENGELS, 2004, p. 69) (grifos nossos).

Vale lembrar que nossa hipótese partia da compreensão de que a educação cumpre um papel predominantemente reprodutor, determinado pelo processo histórico, mas, no entanto, sem deixar de reconhecer as suas contradições. A análise da problemática proposta pela pesquisa e pelo Grupo de Estudo Marxismo e Educação, originada desta, a saber, o papel do complexo educacional no contexto do capitalismo contemporâneo, considerada em sua complexidade histórico-social, suscitou reflexões importantes para a compreensão da práxis educativa, de viés emancipatória, tanto no que se refere ao desvelamento das relações sociais alienantes como para o processo de emancipação humana.

Nesse sentido, examinar a problemática educacional à luz do movimento histórico e das contradições das relações sociais capitalistas trata-se de reconhecer que a educação "[...] é determinada pela sociedade, mas que essa determinação é relativa e na forma de ação recíproca [...] a educação também interfere sobre a sociedade, podendo contribuir para a sua própria transformação" (SAVIANI, 2003, p. 92).

A questão que se apresenta, portanto, é saber em que medida a educação age sobre o determinante - o conjunto das relações sociais dominantes - por meio da ação recíproca, e quais as suas implicações concretas no processo de transformação social. Por isso, a luta no interior das escolas e das universidades em prol de uma educação omnilateral não pode estar descolada da luta pela superação do capitalismo.

$\mathrm{Na}$ esteira desse raciocínio, compreendemos que a constituição de uma escola que propicie a formação omnilateral do ser humano só será possível no terreno da luta política, ou seja, da conquista efetiva da emancipação total ou plena porque "[...] só é tal emancipação porque os sobreditos sentidos e propriedades se tornaram humanos, tanto do ponto de vista subjectivo como objectivo [...]" (MARX, 1993, p. 197). Marx complementa afirmando que:

[...] a objectivação da essência humana, tanto do ponto de vista teórico como prático, é necessária para humanizar os sentidos do homem e criar a sensibilidade humana correspondente a toda a riqueza do ser humano e natural (MARX, 1993, p. 200) (Grifos do autor). 
Nessa direção, Marx (1993, p. 197) enfatiza que a “[...] eliminação da propriedade privada constitui, portanto, a emancipação total de todos os sentidos e qualidades humanas [...]" (MARX, 1993, p. 197).

Engels ressalta que “[...] a indústria praticada em comum, segundo um plano estabelecido em função de um plano feito de acordo com o conjunto da sociedade, implica em homens completos, cujas faculdades tenham se desenvolvido em todos os sentidos e que estejam em condições de ter uma visão clara de todo o sistema produtivo" (MARX; ENGELS, 2004, p. 106). ${ }^{6}$

Nesse sentido, reafirmamos que a construção de uma escola propiciadora de formação omnilateral e, aliado a isso, a luta pela superação da ordem capitalista e pela conquista da emancipação plena são tarefas do conjunto da classe trabalhadora organizada como classe para exercer seu papel revolucionário na história.

Assim, apesar de a escola não se apresentar como o lócus privilegiado da luta de classes, não podemos abdicar de realizar uma intervenção pedagógica emancipatória, reconhecendo seus limites e, ao mesmo tempo, considerando suas contradições e vislumbrando as possibilidades, ainda que sejam limitadas pelo seu caráter globalmente reprodutor.

\section{Referências}

ENGELS, Friedrich. A origem da família, da propriedade privada e do Estado. 2 ed. Tradução de Lenadro Konder. São Paulo: Expressão Popular, 2010.

1982.

. Princípios básicos do comunismo. Lisboa, Portugal: Edições Progresso,

A situação da classe trabalhadora na Inglaterra. Tradução de B. A. Schumann. São Paulo: Boitempo Editorial, 2008.

MANACORDA, Alighiero Mario. Marx e a pedagogia moderna. $2^{\mathrm{a}}$ Ed. Campinas: Editora Alínea, 2007.

MARX, Karl. O Capital - crítica da economia política. Rio de Janeiro: Bertrand Brasil, 1996.

. Crítica do programa de Gotha. Seleção, tradução e notas de Rubens Enderle. São Paulo: Boitempo, 2012.

\footnotetext{
${ }^{6}$ Citação extraída da obra Princípios Básicos do Comunismo (ENGELS, 1982).
}

\begin{tabular}{|l|l|l|l|l|}
\hline Qevista Dialectus & Ano 2 & n. 3 & Julho-Dezembro 2013 & p. 133-144 \\
\hline
\end{tabular}


. Manuscritos econômico-filosóficos. Tradução de Artur Morão. Lisboa, Portugal: Edições 70, 1993.

. A questão judaica. IN: Manuscritos econômico-filosóficos. Tradução de Artur Morão. Lisboa, Portugal: Edições 70, 1993.

Teses sobre Feuerbach. IN: MARX, Karl; ENGELS, Friedrich. A ideologia alemã. 10 ed. Tradução de José Carlos Bruni e Marco Aurélio Nogueira. São Paulo: Hucitec, 1996.

1982.

Trabalho assalariado e capital. Lisboa, Portugal: Edições Progresso,

. Salário, preço e lucro. São Paulo: Editora Edipro, 2004.

MARX, Karl; ENGELS, Friedrich. Textos sobre educação e ensino. Tradução de Rubens Eduardo Frias. São Paulo: Centauro, 2004.

A ideologia alemã. 10 ed. Tradução de José Carlos Bruni e Marco Aurélio Nogueira. São Paulo: Hucitec, 1996.

Manifesto do Partido Comunista. 2 ed. São Paulo: Editora Instituto José Luis e Rosa Sundermann, 2008. (Coleção 10, n. 06).

. A sagrada família, ou, Crítica da crítica crítica contra Bruno Bauer e seus seguidores. Tradução de Sérgio José Schirato. São Paulo: Centauro, 2001.

MÉSZÁROS, István. A educação para além do capital. São Paulo: Boitempo Editorial, 2005.

. Marx: a teoria da alienação. Rio de Janeiro: Zahar, 1981.

SAVIANI, Dermeval. Pedagogia histórico-crítica: primeiras aproximações. 8 ed. revista e ampliada. Campinas: Autores Associados, 2003.

SOUSA JÚNIOR, Justino de. Marx e a crítica da educação: da expansão liberaldemocrática à crise regressivo-destrutiva do capital. São Paulo: Editora Ideias e Letras, 2011.

TONET, Ivo. Educação, cidadania e emancipação humana. Ijuí-RS: Ed. Unijuí, 2005.

\begin{tabular}{|l|l|l|l|l|}
\hline Qevista Dialectus & Ano 2 & n. 3 & Julho-Dezembro 2013 & p. 133-144 \\
\hline
\end{tabular}

